\title{
Genetical aspects of hybrid embryo abortion in the genus Lens $\mathrm{L}$.
}

\author{
S. ABBO* \& G. LADIZINSKY \\ Faculty of Agriculture, Hebrew University of Jerusalem, Rehovot 76100, Israel
}

\begin{abstract}
Hybrid embryo abortion is an effective crossing barrier in the genus Lens L. It divides the genus into two crossing groups: the Culinaris and the Nigricans groups; but it is also evolving within the Culinaris group. The abortion of the $\mathrm{F}_{1}$ embryo is strongly affected by dominant gene action. In the segregating generations embryo abortion is of a quantitative nature and has both components, dominant and additive. These were expressed differentially in the Lens ervoides $\times$ L. culinaris and $L$. orientalis $\times L$. culinaris cross combinations. The genetic control of embryo abortion was indicated further by the association between marker loci and embryo abortion rates in segregating generations. Embryo abortion was not associated with chromosomal aberrations. The establishment of an embryo abortion reproductive barrier by a single somatic mutation in a locus affecting seed development is proposed as a first step in a build-up of genetic isolation in the genus Lens.
\end{abstract}

Keywords: crossing barrier, genetics, hybrid embryo abortion, Lens L., quantitative control.

\section{Introduction}

Wild as well as cultivated lentil are usually free of any embryo abortion following self-pollination. Hybrid embryo abortion after interspecific hybridization in lentil was first described by Ladizinsky et al. (1984). They classified the five taxonomic species of the genus Lens L. into two crossing groups: the Culinaris group, which includes the cultivated lentil Lens culinaris and the wild taxa $L$. orientalis and $L$. odemensis and the Nigricans group, which contains $L$. nigricans and $L$. ervoides. Crossing within each group is usually successful and the resulting $F_{1}$ plants are fully or partially fertile. Crosses between the groups fail due to embryo abortion within 14 days after pollination (Ladizinsky et al., 1984). Interestingly, embryo abortion is also typical to a few cross combinations within the Culinaris group (Brown, 1985). In a recent paper (Abbo \& Ladizinsky, 1991) the authors described the anatomical aspects of hybrid embryo abortion in lentil.

Ladizinsky et al. (1985) obtained an interspecific hybrid between $L$. ervoides and $L$. culinaris using embryo rescue techniques. This $F_{1}$ plant produced normal and aborted embryos at a ratio of 1:1. Among

*Correspondence: The Field Crops Department, Faculty of Agriculture, Rehovot 76100, Israel. the $F_{2}$ progeny, however, pod abortion ranged from 10 per cent to 90 per cent, thus implying quantitative control of embryo abortion (Ladizinsky et al., 1985).

As Lens species are self-pollinated, interspecific embryo abortion is apparently caused by a heterozygous condition, an epistatic interaction or both. Given the fact that continuous variation of embryo abortion was recorded on plants of early segregating generations derived from intra- and interspecific hybrids (Brown, 1985; Ladizinsky et al., 1985), it seems plausible that embryo abortion is a result of multiple gene action.

The genus Lens therefore provides a unique opportunity to study the genetics of crossing barriers between species through hybrid embryo abortion. One possible approach is to look for linkage between marker loci and quantitative trait loci (QTL) affecting embryo abortion (Tanksley et al., 1982). Secondly, narrow sense heritability could provide a valuable estimate for the additive component of genetic variance of embryo abortion in lentil. Thirdly, as parental lines may differ in chromosomal linear order, backcrosses may help to assess the role of chromosomal aberrations, if any, in hybrid embryo abortion. We present a genetic analysis of hybrid embryo abortion in two segregating populations derived from intra- and interspecific cross combinations of lentil. 


\section{Materials and methods}

\section{Plant material}

L. ervoides \# $32 \times$ L. culinaris \# 7. An $F_{1}$ plant was obtained with the aid of embryo culture (Ladizinsky et al., 1985). Sixty-five $F_{5}$ plants originating from 65 individual $F_{2}$ plants were obtained by the single seed descent procedure. Fifty-four $\mathrm{F}_{6}$ families were grown in a randomized design (about seven plants per $\mathrm{F}_{6}$ family) in the greenhouse during Winter-Spring 1990. Thirtyseven $\mathrm{F}_{7}$ families were grown in the greenhouse during Winter-Spring 1991.

L. orientalis \# $133 \times$ L. culinaris \# 2 . Two $F_{1}$ seeds were obtained after approximately 400 hand pollinations (Brown, 1985). Eighty-six $\mathrm{F}_{2}$ plants were grown in Autumn 1987. A random sample of $44 F_{3}$ families (about 12 plants per family, progeny of 44 individual $F_{2}$ plants) were grown as described above during Winter-Spring 1989 . Forty $F_{5}$ families, bulked progeny of $F_{4}$ families were grown as described above during Winter-Spring 1991.

\section{Scoring of aborted embryos}

Aborted embryos were shrunken and smaller (1-2 mm in diameter) than viable seeds. All pods from each plant of the analysed populations were removed before dehiscence. Viable and aborted seeds were counted. For each plant the ratio of aborted seeds, AR, was calculated as follows: $A R=$ No. of aborted seeds/(No. of aborted + viable seeds).

\section{Heritability estimates}

Heritability estimates of transformed AR values were obtained by the correlation coefficient from parent $\times$ offspring correlation after Cahaner \& Hillel (1980). The genetic expectation of heritability estimate is determined by genotype frequencies in the analysed populations. Therefore, marker loci were used to detect mean heterozygosity in the segregating populations of both cross combinations. The basic formulae given by Cahaner \& Hillel $(1990)$ were amended according to the actual decrease in heterozygosity found in both cross combinations.

\section{Chromosome analyses}

Karyotypes were characterized by mitotic root tip chromosomes in Feulgen-stained squash preparations. Meiotic chromosomal behaviour was studied during diakinesis, metaphase I and anaphase I-II in pollen mother cells (PMC) using aceto-carmine preparations.

\section{Isozyme electrophoresis}

Starch gel electrophoresis, isozyme activity staining and genotype scores at the $S k d h$ and $G a l-8.5$ loci were as described by Tadmor et al. (1987) and Wendel \& Weeden (1989), respectively.

\section{DNA polymorphism analyses}

Restriction length markers (RFLP) and random amplified markers (RAPD) were scored with bulked DNA preparations made from more than six plants per family in each of the analysed populations. In this way every analysed family served as a progeny test to detect heterozygosity within the parental population.

RFLP. The RFLP markers were developed by $\mathrm{M}$. Havey (Havey \& Muehlbauer, 1989). DNA preparation, digestion with restriction enzymes, agarose electrophoresis, blotting onto nylon membranes, as well as radioactive probe labelling, autoradiogram development and genotype scores, were as described by Havey \& Muehlbauer (1989).

$R A P D$. Polymerase chain reaction conditions, primer sequences, electrophoresis of amplified products and genotype scores were described by Abbo et al.(1992).

\section{Statistical analyses}

Comparison of genotypic groups (within each marker locus), analyses of variance and correlation analyses were carried out using SAS software (SAS, 1982).

\section{Linkage analyses}

Two point linkage tests were done using the LINKAGE-1 program (Suiter et al., 1983). Because the current lentil genetic map (Weeden et al., 1992) was derived from the $F_{2}$ of the very same $L$. ervoides \# $32 \times L$. culinaris \# 7 cross described herein, marker loci on that map were used as anchors in the two point tests to localize RAPD and morphological markers into established linkage groups. In the same way, markers segregating in the L. orientalis \# $133 \times$ L. culinaris \#2 were localized to the linkage groups described by Havey \& Muehlbauer (1989) for a L. culinaris $\times L$. orientalis mapping population.

\section{Results}

The $F_{1}$ plant of the cross L. ervoides \# $32 \times$ L. culinaris \# ( Le \# $32 \times \mathrm{Lc} \# 7$ ) yielded aborted and viable seeds in a 1:1 ratio (see Ladizinsky et al., 1985). So did 
those from the L. orientalis \# $133 \times L$. culinaris \# 2 (Lo \# 133 × Lc \# 2) which yielded 46:57 and 71:71, aborted:viable seeds, respectively. These ratios may suggest the involvement of one major locus, determining embryo abortion in the heterozygous condition. Under this assumption all heterozygous individuals would be eliminated from the population (as aborted $\mathrm{F}_{2}$ seeds). The viable $F_{2}$ individuals would then represent the two parental homozygous groups, free of subsequent embryo abortion. However, continuous variation in ratios of aborted embryos as found on plants among segregating generations of the Le \# $32 \times$ Lc \# 7 cross, up to $F_{7}$, rules out monogenic control.

The partially fertile interspecific hybrids and the quantitative nature of embryo abortion allowed us to use the following three methods for studying the genetics of hybrid embryo abortion: (1) heritability estimation of embryo abortion ratio, to differentiate between environmental effects, and genetic variation; (2) detection of factors affecting embryo abortion with the aid of marker loci; and (3) backcrosses (BC) to parental lines, to assess crossability relations between the families of segregating generations and the parental lines, and secondly to assess the effect of chromosomal rearrangements on embryo abortion.

\section{Heritability estimation}

Le \# $32 \times L c$ \# 7. Means, ranges and standard deviations of the resultant AR values are given in Table 1. A slight reduction in AR values is evident among the $F_{6}$ families compared with the $F_{5}$ population. The distribution range narrowed and shifted towards the lower values. Nevertheless, the AR distribution among the $F_{7}$ families was still wide and close to that described for the $F_{2}$ generation (10-90 per cent) by Ladizinsky et al. (1985).

By definition, AR values may range from 0.0 to 1.0 and are therefore not normally distributed. To enable analyses of variance and correlation analyses AR values were normalized as follows: Transformed $A R$ $(\mathrm{TAR})=\operatorname{arcsine}($ square $\operatorname{root}(\mathrm{AR}))$. The distribution of TAR values was tested using SAS' Varcomp procedure and was found normal.

The genetic expectation of heritability estimates is determined by genotype frequencies. As deviations from the expected Mendelian segregation were reported for this cross combination (Tadmor et al., 1987), an estimate for genotype frequencies was obtained by six non-linked markers (according to Weeden et al., 1992). Segregation of an $F_{6}$ family in any of the marker loci was interpreted as an indication of heterozygosity in the $F_{5}$ plant. About one-quarter of the $\mathrm{F}_{5}$ plants were found heterozygous, a greater proportion than the expected $1 / 16$ after four generations of selfing (Table 2). As heterozygous frequency in the $\mathrm{F}_{2}$ population was 0.5 (Tadmor et al., 1987) and 0.25 among the $F_{5}$, a reduction of 0.2 , instead of 0.5 , in heterozygous frequency after each generation of selfing apparently took place. Therefore, heritability expectations were accordingly amended based on the basic formulae given by Cahaner \& Hillel (1980) (Table 3).

As a considerable fraction of heterozygosity was detected in the $F_{5}$ generation the heritability expectations are not free of the $V_{\mathrm{D}}$ component (Table 3). The heritability estimate according to the parent $\times$ offspring correlation was $r=0.47 \pm 0.09$.

Lo \# $133 \times L c \# 2$. This population was derived from two $F_{1}$ seeds obtained after 400 hand pollinations (Brown, 1985). Seed set is usually over 50 per cent in crosses within the Culinaris group. Eighty-six $\mathrm{F}_{2}$ progeny were scored for aborted embryos during Autumn 1987. The following morphological markers were also scored: epicotyl coloration $(G s)$, pod pubescence $(H p)$, pod dehiscence $(P d)$, growth habit $(G h)$, hard seed coat $(G e r)$, cotyledon colour $($ Cot $)$ and seed coat pattern $\left(S_{c}\right)$ (Table 4$)$. A random sampling or

Table 1 Descriptive statistics of AR in the segregating populations of the analysed cross combinations

\begin{tabular}{lllll}
\hline $\begin{array}{l}\text { Cross } \\
\text { combination }\end{array}$ & Generation & Mean & Range & $\begin{array}{l}\text { Standard } \\
\text { deviation }\end{array}$ \\
\hline Le\# 32× Lc\#7 & $F_{5}$ & 0.32 & $0.00-0.68$ & 0.189 \\
& $F_{6}$ & 0.22 & $0.01-0.47$ & 0.127 \\
& $F_{7}$ & 0.29 & $0.00-0.89$ & 0.230 \\
Lo\#133×Lc\#2 & $F_{2}$ & 0.30 & $0.06-0.60$ & 0.143 \\
& $F_{3}$ & 0.16 & $0.02-0.34$ & 0.064 \\
& $F_{5}$ & 0.08 & $0.00-0.25$ & 0.060 \\
\hline
\end{tabular}


$44 \mathrm{~F}_{3}$ families was grown and scored for aborted embryos and morphological markers during Winter-Spring 1989. RFLP and RAPD analyses were performed with bulked DNA preparations of $F_{4}$ progeny (to represent the genetic status of the $F_{3}$ family). AR and TAR were calculated as described for the previous cross combinations. Descriptive statistics of $A R$ in the $F_{2}, F_{3}$ and $F_{5}$ generations are given in Table 1. A marked reduction in AR values is evident in $\mathrm{F}_{3}$ compared with $\mathrm{F}_{2}$. A further reduction of AR values was evident among the $F_{5}$ families.

The $\mathrm{F}_{3}$ families were used to detect heterozygosity in the $F_{2}$ generations by the above morphological markers. The number of segregating $\mathrm{F}_{3}$ families for each of those markers is given in Table 2. In all marker loci but the Ger locus, no deviations from the expected Mendelian segregation were found. Therefore, the heritability expectations for TAR (Table 3 ) were as developed by Cahaner \& Hillel (1980). The heritability estimate of TAR obtained by the correlation coefficient was $r=0.54 \pm 0.1$.

Table 2 Number of segregating families of the two analysed cross combinations at morphological and RFLP markers

\begin{tabular}{|c|c|c|c|c|}
\hline \multicolumn{3}{|c|}{ L. ervoides $\times L$. culinaris } & \multicolumn{2}{|c|}{ L. orientalis $\times$ L. culinaris } \\
\hline Locus & $\begin{array}{l}\text { No. } \\
\mathrm{F}_{6} \text { fa }\end{array}$ & $\begin{array}{l}\text { gregating } \\
\text { es }\end{array}$ & Locus & $\begin{array}{l}\text { No. of segregating } \\
\mathrm{F}_{3} \text { families }\end{array}$ \\
\hline Gs & & $14 / 54$ & Gs & $25 / 44$ \\
\hline$P d$ & & $19 / 54$ & $P d$ & $21 / 44$ \\
\hline Ger & & $11 / 54$ & Ger & $17 / 44$ \\
\hline$S t$ & & $14 / 54$ & $G h$ & $21 / 44$ \\
\hline P68 & & $10 / 54$ & $\mathrm{Cot}$ & $28 / 44$ \\
\hline P110d & & $14 / 54$ & Sc & $20 / 44$ \\
\hline \multirow{2}{*}{\multicolumn{2}{|c|}{$\begin{array}{l}\text { Mean } \\
\text { Expected } \\
\quad \text { heterozygous } \\
\text { frequency }\end{array}$}} & $1 / 4$ & & $1 / 2$ \\
\hline & & $1 / 16$ & & $1 / 2$ \\
\hline
\end{tabular}

\section{Genetic association between abortion factors and marker loci}

To pursue further the genetic nature of the factors affecting hybrid embryo abortion we attempted to find an association between this quantitative characteristic and known genetic markers.

Le \# $32 \times L c \# 7$. Within the $\mathrm{F}_{6}$ generation of this cross combination the following markers were scored: morphological markers $G s$, Ger, $P d$, stipule shape $S t$, RFLP markers E14, P68, P110a, P110b, P110c, P110d and 36 RAPD polymorphic bands. Within the $F_{7}$ population, $G s, P d$, $S t$, the isozymic markers $S k d h$ and Gal-8.5 and the RFLP markers C81, E5, P111a and $P 111 d$ were scored. The above genetic markers cover approximately 80 per cent of the lentil genome as estimated by means of chiasmata per cell by Ladizinsky (1979) and according to the proposed map of Weeden et al. (1992).

Among the 38 markers scored in the $F_{6}$ generation two morphological markers, $\mathrm{Pd}$, $\mathrm{Ger}$ and eight RAPD markers were found in association with embryo abor-

Table 4 Monogenic segregation of marker loci as scored in the $F_{3}$ generation of the cross L. orientalis \# $133 \times L$. culinaris \# 2

\begin{tabular}{|c|c|c|c|c|c|c|c|}
\hline \multirow{2}{*}{$\begin{array}{l}\text { Marker } \\
\text { locus }\end{array}$} & \multicolumn{3}{|c|}{$\begin{array}{l}\text { Genotypic } \\
\text { groups }\end{array}$} & \multirow[b]{2}{*}{ Total } & \multirow[b]{2}{*}{ d.f. } & \multirow{2}{*}{$\begin{array}{l}\text { Expected } \\
\text { ratio }\end{array}$} & \multirow[b]{2}{*}{$\chi^{2}$} \\
\hline & cul & het & ori & & & & \\
\hline Ger & 21 & 17 & 4 & 42 & 2 & $1: 2: 1$ & 15.28 \\
\hline$P d$ & 6 & 21 & 13 & 40 & 2 & $1: 2: 1$ & 2.55 \\
\hline$G h$ & 15 & 21 & 7 & 43 & 2 & $1: 2: 1$ & 3.0 \\
\hline$G s$ & 11 & 25 & 7 & 43 & 2 & $1: 2: 1$ & 1.88 \\
\hline$H p^{a}$ & 33 & 33 & 11 & 44 & 1 & $1: 3$ & 0.0 \\
\hline Cot & 8 & 28 & 7 & 43 & 2 & $1: 2: 1$ & 1.37 \\
\hline$S c$ & 12 & 20 & 11 & 43 & 2 & $1: 2: 1$ & 0.26 \\
\hline
\end{tabular}

aScored in $\mathrm{F}_{2}$ only.

Table 3 Estimating procedures and genetic expectations of heritability estimates of TAR for the two analysed cross combinations

\begin{tabular}{|c|c|c|}
\hline Combination & $h^{2}$ estimation procedure & $h^{2}$ genetic expectation \\
\hline \multirow{2}{*}{ Le\# $32 \times$ Lc \# 7} & \multirow{4}{*}{$\begin{array}{l}r=\frac{\operatorname{Cov} \mathrm{F}_{6} \mathrm{~F}_{5}}{\sqrt{V_{\mathrm{F} 6} * \sqrt{V_{\mathrm{F} 5}}}} \\
r=\frac{\operatorname{Cov} \mathrm{F}_{3} \mathrm{~F}_{2}}{\sqrt{V_{\mathrm{F} 3} * \sqrt{V_{\mathrm{F} 2}}}}\end{array}$} & $1.5 V_{A}+0.6 V_{\mathrm{D} D}$ \\
\hline & &  \\
\hline \multirow{2}{*}{ Lo\# $133 \times$ Lc \# 2} & & $V_{\mathrm{A}}+0.5 V_{\mathrm{D}}$ \\
\hline & & 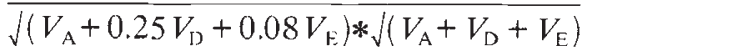 \\
\hline
\end{tabular}


Table 5 Probability of $F$ value obtained by the one-way ANOVA for the effect of the marker loci on TAR in the $F_{6}$ L. ervoides \# $32 \times$ L. culinaris \# 7 population

\begin{tabular}{ll}
\hline Marker locus & $P(F)$ \\
\hline$P d$ & 0.067 \\
Ger & 0.006 \\
$P 3 f$ & 0.03 \\
$P 7 c$ & 0.06 \\
$P 7 d 2$ & 0.03 \\
$P 8 e 2$ & 0.009 \\
$P 8 e 7$ & 0.006 \\
$P 11 d$ & 0.04 \\
$P 11 e$ & 0.007 \\
$P 11 g$ & 0.02 \\
\hline
\end{tabular}

tion (Table 5). Only $P 7 c$ of the eight unmapped RAPD markers was tightly linked to a pair of known markers, $P 110 b$ and $P d$, and was therefore localized in linkage group 3 according to Weeden et al.'s (1992) map.

Lo \# $133 \times L c \# 2$. The seven morphological markers used for the estimation of heterozygosity in the $F_{2}$ and $\mathrm{F}_{3}$ populations were tested for association with embryo abortion factors. In addition, all but the $S c$ locus were found to be linked to each other. These data do not agree with the map proposed by Havey \& Muehlbauer (1989) in which four of the six linked morphological markers were placed onto different linkage groups. As the parental lines differed by at least three reciprocal translocations (Ladizinsky et al., 1984) the 'morphological linkage group' is considered to consist of four chromosomes (out of a total of seven). All the linked markers were found to affect the AR. Most of the RFLP and RAPD markers (data not shown), scored using bulked DNA of $F_{4}$ plants per family, clustered onto the 'morphological linkage group', suggesting that this 'pseudo-linkage' group contains a considerable portion of the genome.

Weller (1987) proposed a method to estimate the effect of a chromosomal segment on a quantitative trait. According to Weller's method the effect of a chromosomal segment defined by two linked markers ( $m$ and $n$ ) is calculated from the means of the QTL value of the two double homozygous groups as follows: Chromosomal segment effect $=X_{\mathrm{m} 1 \mathrm{nn} 11}-X_{\mathrm{m} 22 \mathrm{n} 22}$; where $X_{\mathrm{m} 11 \mathrm{n} 11}$ and $X_{\mathrm{m} 22 \mathrm{n} 22}$ are the means of the $\mathrm{F}_{3}$ families doubly homozygous for the linked markers $m$ and $n$. If the chromosomal segment contains only one QTL for the analysed trait, the accuracy of this approach increases with decreasing map distance between the markers because double recombinants of the two markers are less likely to occur. Surprisingly,
Table 6 Map distances between marker loci in the 'pseudolinkage' group and the calculated effect of chromosomal segment on TAR as defined by pairs of marker loci (after Weller, 1987)

\begin{tabular}{lll}
\hline $\begin{array}{l}\text { Marker } \\
\text { pairs }\end{array}$ & $r(\mathrm{cM})$ & $\begin{array}{l}\text { Effect on embryo } \\
\text { abortion (in TAR units) }\end{array}$ \\
\hline Ger-Gh & 22 & 0.20 \\
Gh-Gs & 32 & 0.21 \\
Gs-Pd & 19 & 0.26 \\
Ger-Pd & 73 & 0.31 \\
\hline
\end{tabular}

the segment defined by the most remote markers Ger$P d$ (Table 6) had the largest effect on the embryo abortion ratio. If embryo abortion were affected by only one locus in the analysed segment then estimating the effect of a larger segment should result in a reduced effect. In this case the opposite was true, i.e. analysis of a larger segment resulted in a much greater effect on embryo abortion.

We interpret this as an indication that embryo abortion is affected by number of loci, as indicated by the analysis of the first cross, where ten marker loci were found to associate with embryo abortion. It is not clear if all these markers represent distinct abortion factors. However, evidence was found for the involvement of several loci in affecting embryo abortion in both cross combinations.

\section{Backcrosses}

Le \# $32 \times L c \# 7$. Thirty-seven $\mathrm{F}_{7}$ families of the cross Le \# $32 \times$ Lc \# 7 were crossed with the parental lines. Of these, 20 crossed freely with Lc \# 7 and partially with Le \# 32. Seven families were crossed successfully to both parental lines, although in some cases a small proportion of aborted seeds was found. Five families did not cross at all with Le \# 32 and crossed partially with Lc \#7. For each family the TAR for two BC directions was calculated. The one-way ANOvA, used for detecting linkage between marker loci and TAR, was adopted for detection of linkage between marker loci and the $A R$ after $B C$ with each of the parental lines.

The E5,P110b and $P 110 \mathrm{c}$ marker loci were found to affect crossability with $\mathrm{Lc} \# 7$. In each of them, the high aborting groups carried the $L$. ervoides alleles. The P110c, St and Gal-8.5 marker loci were found to affect crossability with Le \# 32 . In the first two loci, the high aborting groups carried the $L$. culinaris alleles. These results suggest that embryo abortion after BC resulted from heterozygous interaction (dominant gene action). It is important to note that none of the loci 
which affected TAR in the BC did so after self-pollination on the $\mathrm{F}_{6}$ and $\mathrm{F}_{7}$ plants.

Lo \# $133 \times$ Lc \# 2. Five $\mathrm{F}_{4}$ families of this cross were selected for backcrosses. Three of the families (\#13, 93, 96) were homozygous for the culinaris alleles throughout the 'pseudo-linkage groups'. The other two families (\#26,43) were homozygous to the orientalis alleles in all the analysed markers. Lo \# 133 and Lc \# 2 differ karyotypically from each other (Fig. 1a, b). Lc \# 2 has a large satellite on a metacentric chromosome whereas in Lo \#133 most of the satellite is translocated and the satellited chromosome is very small, hence acrocentric (evidence for translocation in Fig. 1c). The first three families had the satellited chromosome of $\mathrm{Lc} \# 2$ and the other two had the Lo \#133 satellited chromosome. These latter families crossed freely with both parental lines. Two of the three families with the culinaris satellited chromosome (\# 13,93) crossed freely with Lc \#2 but did not cross with Lo \# 133, the third one (\#96) crossed with either parental line, although more freely with Lc \#2.

During Winter-Spring 1991, BC and $F_{5}$ plants of these five families were compared for embryo abortion ratio. Chromosome pairing at meiosis in PMC was studied to verify the hybrid nature of the $\mathrm{BC}$ plants and to assess the effect of chromosomal aberrations on the AR. A one-way ANOVA within each of the families was used for the comparison of TAR values of the two $B C$ groups and the $\mathrm{F}_{5}$ group.

In family \# 13 TAR values were higher in the selfed progeny than in plants from BC with Lc \#2 (Table 7). In families \#43 and 93 the selfed progeny did not differ from the progeny of $\mathrm{BC}$ with $\mathrm{Lc} \# 2$. Families \# 26 and 96 behaved differently. There, seeds from $\mathrm{BC}$ with both parents were obtained. The selfed
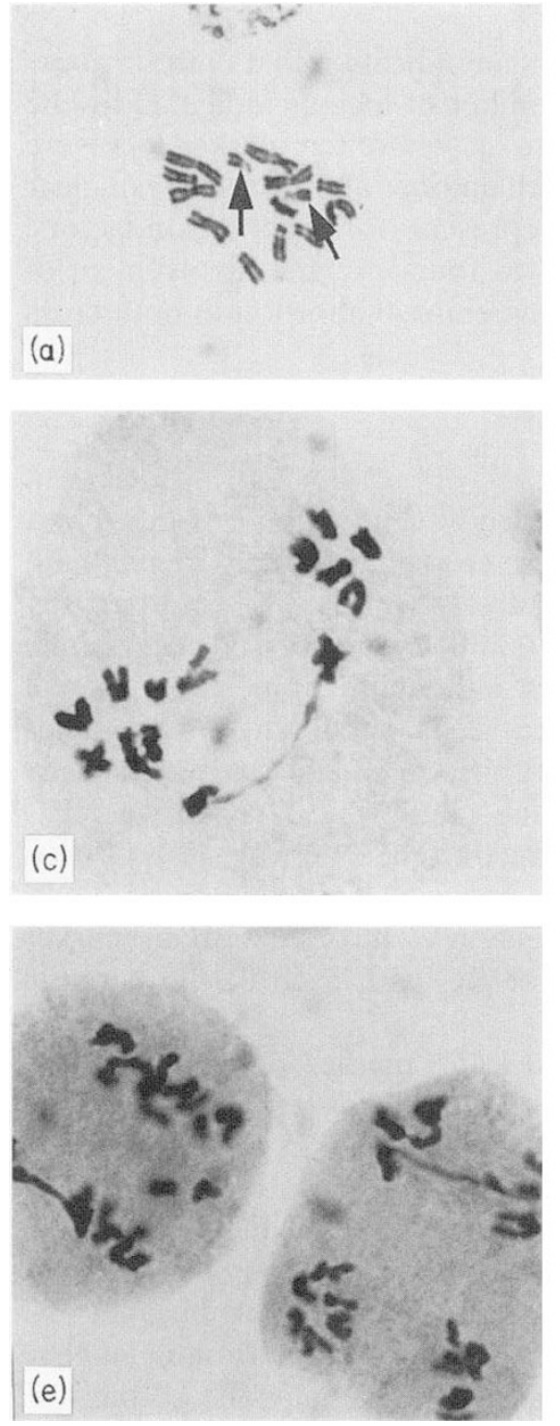
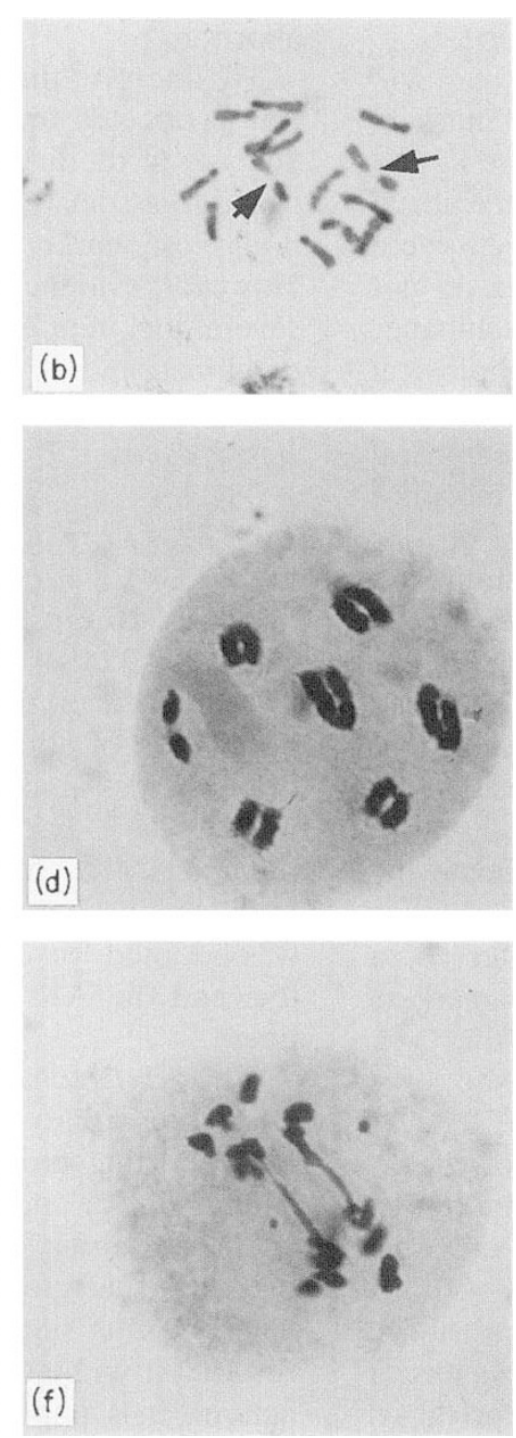

Fig. 1 Karyotypic differences between L. culinaris \# 2 and L. orientalis \# 133 and meiotic behaviour in backcrosses with their $\mathrm{F}_{4}$ derivatives. (a) Karyotype of Lo \# 133, the satellited chromosomes are arrowed. (b) Karyotype of Lc $\# 2$, the satellited chromosomes are arrowed. (c) Anaphase I in a backcross between an $\mathrm{F}_{4}$ plant possessing an Lo \# 133 karyotype and Lc \# 2. Note the asymmetric segregation, evidence for a quadrivalent separated into a trivalent and a univalent. (d) Normal pairing at diakinesis of an $\mathrm{F}_{4}$ plant possessing an Lo \# 133 karyotype. Note the small acrocentric bivalent associated with the nucleolus. (e) Bridges at anaphase II in a backcross plant between an Lo \# 133 and $\mathrm{Lc} \# 2$. Evidence for a paracentric inversion. (f) Anaphase I bridges in a backcross plant between an Lc \#2 type and Lo \# 133. Note the bridges connect two independent pairs of chromosomes. 
Table 7 Probability of $F$ values obtained while comparing the three groups in each family and mean TAR in each of the groups

\begin{tabular}{|c|c|c|c|c|}
\hline \multirow[b]{3}{*}{$\mathrm{F}_{5}$ family } & \multirow[b]{3}{*}{$P(F)$} & \multicolumn{3}{|c|}{ Family TAR values } \\
\hline & & \multirow{2}{*}{$\begin{array}{l}\text { Selfed } \\
\text { progeny }\end{array}$} & \multicolumn{2}{|c|}{ BC direction } \\
\hline & & & $\mathrm{LC \#} 2$ & Lo\# 133 \\
\hline 13 & 0.003 & $0.26^{\mathrm{a}}$ & $0.16^{\mathrm{a}}$ & - \\
\hline 93 & 1.12 & $0.25^{i 1}$ & $0.28^{a}$ & - \\
\hline 96 & 0.075 & $0.23^{a}$ & $0.20^{\mathrm{a}}$ & $0.35^{b}$ \\
\hline 26 & 0.003 & $0.01^{\mathrm{a}}$ & $0.21^{\mathrm{h}}$ & $0.04^{\mathrm{a}}$ \\
\hline 43 & 0.074 & $0.09^{a}$ & $0.17^{a}$ & $0.05^{\mathrm{a}}$ \\
\hline
\end{tabular}

TAR values with the same letter did not differ statistically within families.

progeny did not differ in TAR values from the parental line of the same karyotypic arrangement: progeny of \# $96 \times$ Lo \# 133, \# 26× Lc \# 2 had higher abortion rates than in the selfed progeny of the respective families.

No chromosomal aberrations were found within families (Fig. 1d). Chromosomal aberrations were not found also in BC plants of Lc \# 2 with families \# 13, 93 or 96 nor in BC plants of families \# 26 or 43 with Lo \# 133. On the other hand the BC plants of families \# 26 and 43 with Lc \# 2 were heterozygous for three translocations and two inversions, similar to findings in Lc \# $2 \times$ Lo \# 133 hybrids (Fig. 1c, e). The same was true in the BC plants of family \# $96 \times$ Lo \# 133 (Fig. 1f). This indicates that chromosomal linear order of parties involved in the crosses has no effect on embryo abortion.

\section{Discussion}

A wide range of reproductive barriers has been described in the plant and animal kingdoms. However, understanding the genetic nature of these barriers is difficult because perfect genetic study material is hardly available. Genetic analyses are usually based on progeny tests but reproductive barriers prevent the formation of such progeny. The few existing reports on the genetic aspects of reproductive barriers, at best, present proportions of viable and nonviable progeny in the $\mathrm{F}_{2}$ of interspecific crosses (Gou et al., 1989; Hollingshead, 1930; Parker \& Michaels, 1986; Rabakoarihanta et al., 1979; Shii et al., 1982).

The results of this study indicate that the abortion of $F_{1}$ hybrids is strongly affected by dominant or epistatic gene interaction. In the segregating genera- tions embryo abortion is of a quantitative nature. The genetic nature of embryo abortion is indicated further by the association between abortion rate and several marker loci in the segregating populations.

Despite the assumption that small numbers of genes affect the abortion of the hybrid embryos and those produced by the $F_{1}$ hybrids we could not determine their number. However, that number is assumed to be rather small, as indicated by the proportion of the $F_{4}$ families of the Lo \# $133 \times$ Lc \# 2 and $F_{7}$ Le \# $32 \times$ Lc \# 7 families which freely intercrossed with both parental lines. The association between embryo abortion and several of the marker loci is another genetic property of the abortion. Associations of this kind have been proposed as a tool for mapping QTL (Tanksley et al., 1982; Weller, 1987). In the examined material, some of the factors affecting embryo abortion were mapped to a linkage group which includes the $P d, P I I O b$ and $P I I I b$ loci.

The progress towards homozygosity was much slower in the Le \#32 $\times$ Lc \# 7 cross combination. Despite increasing homozygosity the abortion rate remained virtually the same from $F_{2}$ to $F_{7}$. This high value cannot be solely related to heterozygosity because with a mean heterozygosity of 0.5 in the $F_{2}$ of Lo \# $133 \times$ Lc \# 2, a mean AR of 0.3 was recorded whereas at 0.25 mean heterozygosity in the $F_{5}$ of the Le \# $32 \times$ Lc \# 7, a mean AR of 0.32 was found. The fixed $A R$ value in advanced segregating generations of Le \# $32 \times$ Lc \# 7 may be explained by interactions between different homozygous genes in the recombinant lines.

The TAR heritability estimates indicate a considerable additive effect. However, the fact that the abortion rate declined sharply in advanced generations of the Lo \# $133 \times$ Lc \# 2 cross suggested that dominant effects are more pronounced in this cross combination.

The genetic attributes of hybrid embryo abortion in inter- and intraspecific crosses in the genus Lens shed some light on the evolution of the reproductive barrier. Morphologically Lo \#133 is indistinguishable from other accessions of $L$. orientalis and its isozyme profile is similar to most of the examined $L$. orientalis- $L$. culinaris group (Pinkas et al., 1985). However, Lo \# 133 is unique and differs from the main cytogenetic stock of $L$. orientalis- $L$. culinaris by at least five chromosomal rearrangements and its karyotype (Fig. 1). These rearrangements have no effect on abortion because some $F_{5}$ families with the chromosomal arrangement of Lo \# 133 freely intercrossed with both parental lines. Furthermore, another accession of $L$. orientalis (\#124) which also caused hybrid embryo abortion following crosses with the $L$. orientalis- $L$. culinaris group (data not shown), is similar to the main 
stock of that group. Yet, Lo \# 133 and Lo \# 124 freely intercross with one another and their $F_{1}$ hybrids are free of embryo abortion despite heterozygosity for two reciprocal translocations (data not shown). It seems, however, that in Lo \#124 the mechanism causing abortion with the main stock represented by Lc \# 2 is more effective. A few hybrid seeds can be obtained in the cross Lo \# $133 \times \mathrm{Lc} \# 2$ when the plants are exposed to relatively high temperatures; in the cross Lo \# $124 \times$ Lc \# 2 not only were hybrid seeds never obtained but we could not rescue the hybrid embryos by transplanting them into embryo culture.

The factors governing hybrid embryo abortion in Lo \# $133 \times \mathrm{Lc} \# 2$ are apparently different from those affecting abortion in the L. ervoides $\times \mathrm{Lc} \# 2$ crosses and result in embryo abortion in crosses between Lo \# 124, 133 and all L. ervoides tested. It is thus important to note that embryo abortion, which has similar anatomical characteristics in different crosses (Abbo \& Ladizinsky, 1991), may be governed by different genetic systems.

The establishment of a reproductive barrier is a prerequisite for the formation of a new species. The evolution of these barriers is quite clear when it is based on chromosomal rearrangements but is much more obscure when it is an outcome of physiological and anatomical processes. In the genus Lens, which is predominantly a selfer, the evolution of a genetic mechanism which causes hybrid embryo abortion is not likely to have resulted from selection for achieving isolation from other members of the species or from other species. It could have occurred as a random process or as a by-product of selection for another trait. In any case, a mutation which affects embryo abortion is not likely to occur in the gametes because the heterozygous embryos would abort and the mutation would be lost. On the other hand, mutation in the shoot meristem would produce heterozygous inflorescences. Under self-pollination the heterozygous embryos would abort and the developing homozygous embryos would give rise to two reproductively isolated lines. This hypothetical course of evolution is a rather rapid one and results in speciation after a single step. Accumulation of additional mutations in minor genes could increase the genetic isolation between those lines.

\section{References}

ABBO, S. AND LADIZINSKY, G. 1991. Anatomical aspects of hybrid embryo abortion in the genus Lens. Bot. Gaz., 152, 316-320.

ABBO, S., LADIZINSKY, G. AND WEEDEN, N. F. 1992. Genetic analysis and linkage study of seed weight in Ientil. Euphytica, $\mathbf{5 8}, 259-266$.
BROWN, D. 1985. Anatomical and genetic characterization of embryo breakdown in the genus Lens. M.Sc Thesis, Faculty of Agriculture, The Hebrew University of Jerusalem (Hebrew).

CAIAANER, A. AND HILLEL, J. 1980. Estimating heritability and genetic correlation between traits from generations $F_{2}$ and $\mathrm{F}_{3}$ of self-fertilizing species: a comparison of three methods. Theor. Appl. Genet., 58, 33-38.

GOU, M., MOK, S. W. D. AND MOK, M. C. 1989 . Isozyme banding pattern and embryo development in interspecific crosses of Phaseolus. J. Hered., 80, 29-32.

HAVEY, M. AND MUEHLBAUER, F. J. 1989. Linkage between restriction fragment length, isozyme and morphological markers in lentil. Theor. Appl. Genet., 77, 395-401.

HOLLINGSHEAD, L. 1930. A lethal factor in Crepis effective only in an interspecific hybrid. Genetics, 15, 114-140.

LADIZINSKY, G. 1979. The origin of lentil and its wild genepool. Euphytica, 28, 179-187.

LADIZINSKY, G., BROWN, D., GOSHEN, D. AND MUEHLBAUER, F. J. 1984. The biological species of the genus Lens L. Bot. Gaz., 145, 253-261.

LAdIZINSKY, G., COHEN, D. AND MUEHLbAUER, F. J. 1985. Hybridization in the genus Lens by means of embryo culture. Theor. Appl. Genet., 70, 97-101.

PARKER, J. P. AND MICHAELS, T. E. 1986. Simple genetic control of hybrid plant development in interspecific cross between Phaseolus vulgaris L. and P. acutifolius A. Gray. Plant Breeding, 97, 315-323.

PINKAS, R., ZAMIR, D. AND LADIZINSKY, G. 1985. Allozyme divergence and evolution in the genus Lens. Pl. Syst. Evol., 151, $131-140$.

RABAKOARIHANTA, A., MOK, D. W. S. AND MOK, M. c. 1979. Fertilization and early seed development in reciprocal interspecific crosses of Phaseolus. Theor. Appl. Genet., 54, 55-59.

SAS INSTITUTE 1982. SAS User's Guide: Basics and Statistics. SAS Institute, Cary, N. Carolina.

SHII, C. T., RABAKOARIHANTA, A., MOK, M. C. AND MOK, D. W. S. 1982. Embryo development in reciprocal crosses of Phaseolus vulgaris L. and P. coccineus Lam. Theor. Appl. Genet., 62, 59-64.

SUITER. K. A., WENDEL, J. F. AND CASE, J. S. 1983. LINKAGE- I: a PASCAL program for the detection and analysis of genetic linkage. J. Hered., 74, 203-204.

TADMOR, Y., ZAMIR, D. AND LADIZINSKY, G. 1987. Genetic mapping of an ancient translocation in the genus Lens. Theor. Appl. Genet., 73, 883-892.

TANKSLEY, S. D., MEDINA-FILHO, H. AND RICK, C. M. 1982. Use of naturally-occurring enzyme variation to detect and map genes controlling quantitative traits in an interspecific backcross of tomato. Heredity, 49, 11-25.

WEEDEN, N. F., MUEHLBAUER, F. J. AND LADIZINSKY, G. 1992. Extensive conservation of linkage relationship between pea and lentil genetic maps. J. Hered., 83, 123-129.

WELLER, J. I. 1987. Mapping and analysis of quantitative trait in Lycopersicon (tomato) with the aid of genetic markers using approximate maximum likelihood methods. Heredity, 59, 413-421.

WENDEL, J. F. AND WEEDEN, N. F. 1989. Visualization and interpretation of plant isozymes. In: Soltis, D. and Soltis, P. (eds) Isozymes in Plant Biology, pp. 5-45. Discorides Press, Portland. 